\title{
УДК 81’25
}

\section{ГЕНДЕР КАК ОБЪЕКТ ОЦЕНКИ В МЕДИЙНОМ ДИСКУРСЕ (на материале англоязычных и русскоязычных СМИ)}

\author{
О.Д. Цветкова \\ Тверской государственный университет, г. Тверь
}

\begin{abstract}
В статье рассматриваются различные формы оценки в дискурсе СМИ гендерных характеристик участников общественно-политических процессов в англоязычных странах и России. Определена ретроспективная динамика содержания данной оценки, а также формы - скрытые и открытые - ее выражения.

Ключевые слова: гендер, дискурс, медийный дискурс, оценка.
\end{abstract}

Изучение дискурса как «речи, погруженной в жизнь», ведется по двум направлениям. С одной стороны, это изучение дискурсивных практик, реализующихся в определенной сфере жизни, a, с другой, это рассмотрение тех аспектов «жизни», где эти практики реализуются. Но есть и третий путь, синтезирующий результаты двух первых подходов и выводящий эти результаты на новый уровень - это определение того, как в процессе взаимодействия взаимо-видоизменяются и речь, и жизнь, в которую эта речь погружена. Именно данная диалогическая динамика является основным объектом анализа дискурса.

Наиболее «реактивным» по отношению к жизни является дискурс СМИ. Одной из самых динамичных сфер жизни, где изменения происходят на наших глазах, являются гендерные отношения. Как взаимодействуют дискурс СМИ и гендер, и какова динамика этих отношений в двух крупнейших культурах и культурных традициях, англо-саксонской и славянской, и как реализуется (в явной и скрытой формах) оценка гендерных отношений и ценностей - таков объект настоящего исследования.

Сегодня феминистское движение становится все более заметным в медиа пространстве в России и на Западе. Феминизм уже не просто гендерное и социальное движение, это часть политической борьбы и массовой культуры.

Такие термины как «феминизм» и «феминистка» на Западе всегда имели политическое значение. За последние 40 лет, во время второй и третьей волн феминизма, и в последнее время, в период пост-феминизма, эти два понятия, в основном, носят отрицательную коннотацию в массовой культуре, СМИ и повседневной жизни западного мира. Описания и представления социополитического движения «феминизм» и его сторонников - «феминисток» - в англоязычных печатных изданиях преимущественно пренебрежительны и уничижительны. По словам австралийского исследователя феминизма К. Шаффер, «феминизм» стал отпугивающим словом в массовой и медиа культуре [4: 322]. И спустя два десятилетия оно также вызывает пренебрежение и подкрепляет стереотипы о женщинах.

СМИ имеют значительное влияние в установлении гендерных ролей, и в том числе, освещая вопросы феминизма и его целей. Большинство людей черпают информацию о том, что же представляют собой «феминизм» и 
«феминистки», из СМИ, а не из образовательных курсов [3: 183]. Но какое же значение эти термины имеют для самих журналистов, которые принимают активное участие в создании феминистских и антифеминистских новостей, и какую позицию они занимают по отношению к ним? Актуальным является также вопрос о субъективности журналистов и факторах, влияющих на их отношение к этим новостям.

Некоторые феминистки утверждают, что СМИ склонны к созданию негативного и даже враждебного имиджа феминизма: начиная от высмеивания этого движения, заканчивая нападками на его активных представительниц [5: 25]. Феминизм подвергается критике и осуждению: «слово на букву Ф» [8: 16], «отпугивающее слово» [4: 322], «ругательное слово» [1: 139]. Британская исследовательница И. Велехан [8: 16] утверждает, что «феминизм и его расцвет в середине $70-x$ гг. 20 в. представляет собой оппозиционное и многообещающее движение, позволяющее женщинам отождествлять себя с угнетенным меньшинством, которое может получить власть в борьбе против предубеждений о женщине и женственности». В настоящее время термин «феминизм» утратил свой первоначальный многообещающий потенциал по причине мощной обратной реакции общества [2]. Негативный отклик в СМИ на деятельность феминисток происходит из-за изображения их как «чрезмерно агрессивных, мужененавистниц» [2]. Феминизм сегодня - это «бранное слово, воспринимаемое как догма, которая промыла мозги целому поколению женщин, заверяя их в возможности быть у власти» [8: 16]. По словам К. Шаффер «нескончаемые нападки на феминисток в СМИ должны сыграть свою роль в снижении их политической активности» [4: 328]. Вследствие негативной обратной реакции общества, термин «феминизм» был заменен некоторыми представителями СМИ на уничижительное «фемонаци». При этом, в связи с развитием культуры политкорректности, открытые негативные оценки сменяются оценками скрытыми. Так, контаминант «фемонаци», инкорпорирующий в свой состав сему «наци», соотносит феминистской движение с нацистами, включая в свою семантическую структуру очень мощный пейоративный компонент.

Велехан и Шаффер не одиноки в своих убеждениях. Американка Д. Бейкер Бек [1: 141] подчеркивает, что феминизм стал ругательным словом из-за неприязни СМИ к «активным, напористым женщинам», и то, каким образом СМИ преподносят их, превратило феминисток в «феномен, выходящий за рамки общепринятого».

Однако, не все представители СМИ сосредоточены на негативных представлениях о феминизме. Австралийские исследователи С. Шеридан, С. Маргари и С. Лилберн рассматривают многообразие репрезентаций феминизма в своей работе об австралийских печатных СМИ: «неважно как мы его именуем, какие характеристики ему приписываем, феминизм сегодня - это сила, с которой мы должны считаться» [5: 25].

«Марши женщин», прошедшие по всему миру, подчеркнули популярность темы борьбы за равноправие полов и продемонстрировали поддержку феминистического движения со стороны медийных личностей. По мнению «The Guardian», активный всплеск поддержки этого движения несет в себе отрицательные моменты: тренд 
причислять себя к феминисткам превращает борьбу за гендерное равноправие в рекламную кампанию, которая скрывает истинные цели феминизма [6].

Если некоторые авторы считают феминизм определенным позитивным началом и источником оздоровления политической жизни США, то «The Observer» полагает, что именно феминистическая активность является преградой в установлении взаимопонимания России и Запада. В статье «Почему Путин нас ненавидит» журналист утверждает, что культурная стагнация России не позволяет урегулировать отношения России и США [7], причем, именно отрицательное отношение к феминистскому движению и является симптомом этой стагнации.

Таким образом, при наличии разнополярных мнений относительно феминистского движения в англоязычных СМИ, все-таки, можно сделать вывод об определенной динамике в оценке и понятия «феминизм», и стоящих за ним реалий - это сдвиг в сторону отрицательного отношения, что очевидно при анализе всех средств дискурсивной реализации данной интенции в СМИ.

Проблема гендерной несвободы довольно ярко освещается и в отечественных СМИ. В конце прошлого столетия проявления сексизма в рекламе и СМИ не были редкостью. При этом оспаривание стереотипов о месте женщины воспринималось негативно. Ситуация изменилась несколько лет назад: представители СМИ начали говорить о «гендерном программировании», закладываемом в человека через семейные ценности. В медиа пространстве стали освещаться различные случаи гендерного неравенства. Таким образом, современные СМИ занялись деконструкцией стереотипов о феминистках.

Стали появляться проекты с феминистским уклоном, медиа издания начали уделять внимание проблемам сексизма и развитию феминизма в России [10]. Женские журналы, ранее помещавшие женщину в строго отведенное ей пространство - дом и кухню, заговорили о двух разных подходах - традиционном и феминистическом. Например, «Cosmopolitan» периодически включает в свои издания материалы об идеях равноправия [9].

Не стоит забывать, что феминизм является в большей степени политическим движением, и количество новостей, публикуемых о нем сейчас, вызывает в обществе острую реакцию, так как общество привыкло к более традиционным установкам. Однако, именно от отношения журналистов к вопросу зависит его принятие или отвержение обществом.

Тем не менее, российские СМИ зачастую не справляются со своей задачей и представляют феминизм и феминисток в неадекватном свете. Например, слово «женщина» часто выносится в заголовок в свете ее деятельности. В случае, когда нет необходимости подчеркивать, что именно женщина пользуется базовыми права человека, героиня медийного материала встречается с агрессивным или пренебрежительным отношением.

Другим немаловажным вопросом является освещение деятельности радикальных «псевдофеминистских» групп. Обычно деятели СМИ не вдаются в подробности или путают движение феминизма с активностью отдельных социальных групп. Например, в своей статье «Одеяло угнетало, обижала простыня. Как российские феминистки ненавидят мужчин в сети» Д. Саркисов [12] намеренно или случайно некорректно называет феминистической деятельностью высказывания представительниц некоего сообщества. Таким образом у аудитории складывается ложное представление о феминизме. При этом негативная коннотация 
скрытым образом реализуется за счет использования намеренно искаженного в своей структуре и семантике прецедентного феномена - известной поэмы К. Чуковского, темой которой, как известно, является осмеяние нерях и грязнуль. С ними - через реализацию механизмов прецедентности - и ассоциируются участницы феминистского движения.

Еще одной проблемой является проявление гендерной ненависти и дискриминации по половому признаку. Так, авторы отдельных материалов поддерживают патриархальные стереотипы. Например, автор материала «Бабе дорога - от печи до порога» Е. Чинкова не описывает новость о заколачивании офиса «Femen» досками с объективной точки зрения, а даже призывает к прямому насилию: «... лучше бы повоспитывали тут же на глазах у всех. Эффектнее было бы и эффективнее». [13] Более того, автор выражает свое негативное отношение к феминисткам. В своей статье Е. Чинкова называет активисток «распоясавшимися девицами-феминистками» и «полуголыми спильщицами крестов». Автор целенаправленно, пользуясь уже прямыми средствами реализации негативной оценки, вызывает агрессию у читателей по отношению к феминисткам. Подобные публикации не могут иметь оправданий некорректному освещению феминизма в СМИ.

Тем не менее, с начала 1990-х гг. российские СМИ далеко продвинулись в вопросе необходимости уравнивания гендеров. В отечественных медиа текстах стали использоваться такие термины как «гендер», «объективация», «феминизм». Однако, все же нередко встречаются некорректные или заведомо негативные освещения движения феминизма. Журналисты склонны умалчивать детали, подменять понятия, завуалировать истинные цели, подвергать критике и открыто негативно высказываться об этом движении.

Более либеральные издания, такие, как «Новая Газета» в статье «Феминистки захватили Кремль» проявляют определенную симпатию и позитивное отношение к активисткам, изображая их целеустремленными борцами за гендерное равноправие [11].

Один из новостных сайтов России, «Медуза», опубликовал подробную статью об истории феминизма, его основных принципах и идеях, и также о современном положении проблемы в России, а именно о дискриминации прав женщин [10]. Целью данной статьи было дать описание движения, ответить на основные вопросы и развеять мифы и стереотипы о феминизме.

Более лояльную позицию по отношению к феминизму в России занимают медиа издания, входящие в состав «Look at media». Так, «The Village» часто и подробно затрагивает новости о феминистском движении в России. Например, это издание чуть ли не единственное в нашей стране положительно отзывающееся о «Femen» и «FemFest».

Таким образом, российский медийный дискурс также демонстрирует определенную динамику в оценке реалий, связанных с понятием «феминизм», но это динамика скорее положительная - уже хотя бы потому, что данная проблематика стала адекватно освещаться в средствах массовой информации.

Соотнесение англоязычного и русскоязычного дискурса СМИ, в рамках которого освещаются проблемы гендерных отношений, позволяет ставить широкий спектр вопросов лингвокультурологии и, в частности, вопросы сравнительно-сопоставительного исследования различных способов 
выражения оценки наиболее острых вопросов современной культуры скрытой и открытой.

\section{Список литературы}

1. Baker Beck D. The F-Word: How the Media Frame Feminism // NWSA Journal 10(1), 1998: P.139-153.

2. Faludi S. Backlash: The Undeclared War against American Women. New York: Doubleday, 1991.

3. Huddy L. Feminists and Feminism in the News // Pippa Norris (ed.) Women, Media, and Politics. New York: Oxford University Press, 1997, P.183-204.

4. Schaffer K. Scare Words: Feminism, Postmodern Consumer Culture and the Media // Continuum: Journal of Media \& Cultural Studies 12(3), 1998: P. 321-334.

5. Sheridan S., Magarey S. and Lilburn S. Feminism in the News // Joanne Hollows and Rachel Moseley (eds) Feminism in Popular Culture, Oxford: Berg, 2006, P. 25-40.

6. The Guardian URL: https://www.theguardian.com/commentisfree/2014/oct/10/-spjennifer-lawrence-emma-watson-feminists-celebrity

7. The Observer URL: http://observer.com/2016/11/why-vladimir-putin-hates-us/

8. Whelehan I. Overloaded: Popular Culture and the Future of Feminism. London: The Women's Press, 2000.

9. Грибацкая С. Ты против феминизма? Посмотри во что превратится твоя жизнь без него // Cosmopolitan. URL: https://www.cosmo.ru/lifestyle/society/ty-protivfeminizma-posmotri-vo-chto-prevratitsya-tvoya-zhizn-bez-nego/

10. Медуза URL: https://meduza.io/feature/2017/03/06/stydnye-voprosy-pro-feminizm

11. Новая Газета URL: https://www.novayagazeta.ru/articles/2017/03/08/71717feministki-zahvatili-kreml

12. Саркисов Д. Одеяло угнетало, обижала простыня. Как российские феминистски ненавидят мужчин в сети // Lenta.ru. URL: https://lenta.ru/articles/2016/04/09/femenpablos/

13. Чинкова Е. Бабе дорога - от печи до порога. // Комсомольская правда. URL: http://www.irk.kp.ru/daily/25945.4/2889633/

\section{GENDER AS THE OBJECT OF EVALUATION IN MEDIA DISCOURSE (on English and Russian mass media)}

\section{O.D. Tsvetkova}

Tver State University, Tver

The article debates various forms of evaluation of gender in media in Anglo-Saxon and Russian press. The retrospective dynamics of its content, as well as the forms of this evaluation, are disclosed.

Key words: gender, discourse, media discourse, evaluation.

\section{Об авторе:}

ЦВЕТКОВА Ольга Дмитриевна - аспирантка кафедры теории языка и перевода Тверского государственного университета; e-mail: tsvolga@ bk.ru. 